\title{
UMA VISÃO PECULIAR SOBRE A CULTURA NACIONAL: A "TOURADA PORTUGUESA" COMO METÁFORA
}

\begin{abstract}
Indagado sobre o que lhe parecia distinto na cultura portuguesa, Hofstede (1997) respondeu: "Portugal é um país tipicamente latino, pertencendo, por isso, ao grupo mais feminino. No entanto, reconheci imediatamente que os portugueses diferem dos outros países latinos e, ao contrário dos espanhóis, não matam os seus touros. Os portugueses tendem a ser mais simpáticos para as pessoas e são bons negociadores, tentando sempre encontrar uma via pacífica. Por isso, resolvem muitos problemas negociando, e não guerreando" (p. 40). Gannon, num livro (2001) destinado a comparar as culturas de 23 nações, conotou Portugal com uma metáfora: "Tourada portuguesa”. Neste artigo, far-se-á luz interpretativa sobre vários estudos realizados em Portugal, os quais apontam em vários sentidos: (a) o perfil motivacional mais frequente em amostras portuguesas segue a seguinte hierarquia, por ordem decrescente: afiliação, sucesso, poder; (b) este perfil é consonante com o outrora extraído por McClelland (1961); (c) na linha da hipótese de McClelland (1987, 1992), os trabalhos realizados em Portugal sugerem que o perfil de liderança mais eficaz combina elevadas motivações para o poder e para a afiliação; (d) de entre os 4 estilos comunicacionais aventados por Alessandra e Hunsaker (1993), o mais frequente (e considerado mais eficaz) é o afiliativo/relacional. Esta convergência afiliativa/relacional sugere a necessidade de os gestores serem cautelosos na "importação" de técnicas e modelos que podem ferir o traço "feminino" português - porventura mais sedento de consideração individualizada, comunicação afiliativa/social e "diplomática", harmonia interpessoal, gestão cooperativa de conflitos.
\end{abstract}

Arménio Rego*

Palavras-chave: Feminilidade, afiliação, cultura

* Docente do Departamento de Economia, Gestão e Engenharia Industrial da Universidade de Aveiro 
Asked about what is distinctive in the Portuguese culture, Hofstede answered: "Portugal is a typical Latin country, pertaining to the more feminine group. However, I realized immediately that Portuguese are different from the other Latin countries and, contrarily to the Spanish, they don't kill the bull. The Portuguese tend to be more sympathetic and they are good negotiators, always trying to found a pacific way. Therefore, they solve many problems by negotiating, not fighting. Gannon, in a book (2001) aiming to compare the cultures of 23 nations, also connoted Portugal with a metaphor: "The Portuguese bullfight". In the present paper, we will try to extract some insights from several studies performed in Portugal, which suggest the following: (a) the motivation profile more frequent in Portuguese samples is, by decreasing order, affiliation, achievement and power; (b) this profile is similar to the one suggested several decades ago by McClelland (1961); (c) the more effective leadership profile seems to be the one that combines high power motivation with high affiliation; (d) the communication style more frequent and the one evaluated as more effective is the "relater style" (Alessandra \& Hunsaker, 1993). This empirical evidence suggests to managers the need to be cautious about the "importation" of techniques and models that can conflict with the Portuguese "feminine" trait.

Key words: femininity; affiliation; culture

\section{O MODELO CULTURAL DE HOFSTEDE - PORTUGUESES SÃO FEMININOS, NÃO MACHOS}

O tetra-modelo das culturas nacionais de mais amplo recurso investigativo e explicativo continua a ser o proposto por Hofstede (1980, 1991). Com larga tradição no domínio dos estudos organizacionais - a que, porventura, não é alheio o facto de englobar uma das mais amplas amostras transnacionais que se conhece - o modelo sugere que as diversas culturas nacionais podem ser caracterizadas à luz de quatro dimensões: distância hierárquica, individualismo-colectivismo, evitamento da incerteza e masculinidade-feminilidade:

a) A distância hierárquica reflecte o grau de deferência que os indivíduos projectam sobre os seus superiores hierárquicos, assim como a necessidade de manter e respeitar um afastamento (social) entre um líder e os seus subordinados. Nos países e regiões de elevada distância (e.g., Portugal, Espanha, América Latina, Ásia e África), superiores e subordinados consideram-se desiguais por natureza. A distância emocional entre chefias e subordinados é elevada. Detecta-se uma grande reverência pelas figuras de autoridade, e atribui-se grande importância aos títulos e status. Ao contrário, em países com baixa distância hierárquica (e.g., EUA, Grã-Bretanha e países não latinos da Europa), a 
dependência dos subordinados relativamente aos chefes é limitada. Os primeiros não sentem desconforto considerável por contradizer os segundos. Uns e outros consideram-se iguais por natureza.

b) A dimensão individualismo-colectivismo caracteriza o grau em que a identidade individual é definida com base nos objectivos e realizações pessoais ou em função dos interesses colectivos dos grupos aos quais o indivíduo se encontra ligado. Nos países fortemente individualistas (e.g., Austrália, Grã-Bretanha, EUA, Canadá, Países Baixos), espera-se que as pessoas actuem sobretudo em prol do seu próprio interesse e dos interesses da sua família mais próxima. Em culturas tipicamente colectivistas (e.g., Colômbia, Paquistão, Venezuela, Guatemala), as pessoas tendem a colocar os interesses do grupo e da comunidade em lugar primordial, esperando em troca receber lealdade. Existe uma certa tendência para que os países mais individualistas sejam, também, os caracterizados por menor distância hierárquica.

c) O evitamento da incerteza reflecte o grau de desconforto que as pessoas sentem perante o risco $\mathrm{e}$ as incertezas, o nível de aceitação/rejeição da novidade e da diferença, assim como o grau de importância conferida à estabilidade e ao planeamento. Nos países onde esta característica se detecta em elevado grau (e.g., Grécia, Portugal, Japão, Uruguai), esse sentimento exprime-se em stress, necessidade de previsibilidade, busca de regras e de segurança. Nos países com baixo índice de evitamento (e.g., Singapura, Hong-Kong, Dinamarca, Suécia), parece existir uma aversão emocional às regras formais, só se estabelecem normas em caso de absoluta necessidade, toleram-se mais facilmente os comportamentos desviantes.

d) A masculinidade e feminilidade representam, também, os extremos de uma dimensão que tem, num pólo, o alcance de objectivos e a ambição e, no outro a ênfase na harmonia interpessoal. Nas sociedades mais masculinas (e.g., Japão, Áustria, Venezuela, Suíça), os homens e mulheres têm papéis bem distintos: o homem deve ser forte, impor-se e interessar-se pelo sucesso material, enquanto se espera que a mulher seja mais modesta, terna e preocupada com a qualidade de vida. Nas mais femininas (e.g., Suécia, Dinamarca, Noruega, Países Baixos), espera-se que homens e mulheres sejam modestos, ternos, preocupados com a qualidade de vida, a preservação do ambiente e a ajuda aos outros. 
Quadro I

CULTURAS NACIONAIS DE ALGUNS PAÍSES, SEGUNDO O MODELO DE HOFSTEDE (1991)

\begin{tabular}{lcccc}
\hline País & $\begin{array}{c}\text { Distância } \\
\text { hierárquica }\end{array}$ & Individualismo & Masculinidade & $\begin{array}{c}\text { Controlo da } \\
\text { incerteza }\end{array}$ \\
\hline Portugal & $\mathbf{6 3}$ & $\mathbf{2 7}$ & $\mathbf{3 1}$ & $\mathbf{1 0 4}$ \\
Alemanha & 35 & 67 & 66 & 65 \\
Brasil & 69 & 38 & 49 & 76 \\
Canadá & 39 & 80 & 52 & 48 \\
Espanha & 57 & 51 & 42 & 86 \\
EUA & 40 & 91 & 62 & 46 \\
França & 68 & 71 & 43 & 86 \\
Grã-Bretanha & 35 & 89 & 66 & 35 \\
Japão & 54 & 46 & 95 & 92 \\
\hline
\end{tabular}

A posição de Portugal é, nesta matéria, assim caracterizável (Quadro I): média distância hierárquica, equilíbrio entre o individualismo e o colectivismo, baixa masculinidade (ou elevada feminilidade) e elevado evitamento da incerteza. Este pendor feminino induziu Sakellarides a intitular uma entrevista a Hofstede do seguinte modo: "latinos são femininos, não machos". O título tenta fazer juz à resposta que Hofstede facultou à jornalista quando indagado sobre o que lhe parecia distinto na cultura portuguesa: "Portugal é um país tipicamente latino, pertencendo, por isso, ao grupo mais feminino. No entanto, reconheci imediatamente que os portugueses diferem dos outros países latinos e, ao contrário dos espanhóis, não matam os seus touros. Os portugueses tendem a ser mais simpáticos para as pessoas e são bons negociadores, tentando sempre encontrar uma via pacífica. Por isso, resolvem muitos problemas negociando, e não guerreando" (HOFSTEDE, 1997: 40).

Notavelmente, Gannon, num livro ainda mais recente (2001), destinado a comparar as culturas de 23 nações, reiterou a referência feita por Hofstede e conotou Portugal com uma metáfora: "Tourada portuguesa" - contrastando-a também com a tourada espanhola. É objectivo deste artigo facultar uma visão sinóptica interpretativa de vários estudos empíricos efectuados em Portugal por Rego (e.g., REGO, 1993, 1995, 1998a, 1998b, 2000a, 2001a; REGO e CARVALHO, 2001, 2002) e que sugerem uma propensão portuguesa para a afiliação e as relações interpessoais. Genericamente, tais dados apontam nos seguintes sentidos:

a) A afiliação tende a predominar no perfil motivacional português.

b) $\mathrm{O}$ perfil gizado por essas investigações é consonante com a configuração outrora extraída por McClelland (1961) a respeito de Portugal. 
c) Na linha da hipótese gizada por McClelland e seus colaboradores (McCLELLAND, 1987, 1992), os trabalhos de Rego sugerem que o perfil de liderança mais eficaz em Portugal combina elevadas motivações para o poder e para a afiliação.

d) De entre os 4 estilos comunicacionais aventados por Alessandra e Hunsaker (1993), o mais comum parece ser o afiliativo/relacional (aprecia relações pessoais de proximidade, evita o conflito interpessoal, procura apoio dos outros, denota forte necessidade de pertença). Esse é, também, o estilo considerado mais eficaz pelos inquiridos.

\section{PROEMINÊNCIA MOTIVACIONAL AFILIATIVA}

Os motivos ocupam um lugar importante no elenco dos diversos elementos psicológicos que compõem a personalidade dos indivíduos (WINTER, 1998). Podem ser definidos como as predisposições específicas interiorizadas pelas pessoas através do processo de socialização, as quais se organizam sob forma hierárquica (perfil, diversa de indivíduo para indivíduo) e imprimem uma determinada direcção ao comportamento (RETO et al., 1989/90). Os motivos predominantes nos inúmeros trabalhos de McClelland e seus colaboradores são os de sucesso, afiliação e poder. Podem ser assim caracterizados (McCLELLAND, 1987; KOESTNER e McCLELLAND, 1992; McCLELLAND e KOESTNER, 1992; WINTER, 1998):

a) O motivo de sucesso representa uma orientação para a excelência, uma preferência por riscos moderados, a procura de feedback tendo em vista melhorar o desempenho. As pessoas fortemente motivadas para o sucesso tendem a ser "irrequietas" na sua actividade e a ser bem sucedidas como empreendedoras.

b) O motivo afiliativo representa uma orientação por relações "quentes" e amistosas. As pessoas vincadamente afiloativas tendem a agir amigável e cooperativamente, embora possam actuar irada e defensivamente sob condições de ameaça.

c) O motivo de poder envolve uma orientação para o prestígio e a produção de impacto nos comportamentos ou emoções das outras pessoas. Uma elevada motivação para o poder está associada a actividades competitivas e assertivas, assim como ao interesse em alcançar e manter prestígio e reputação.

Das diversas pesquisas realizadas por Rego (REGO, 1993, 1995, 1998a, 2000a; REGO e CARVALHO, 2001), tem sido extraído, recorrentemente, o mesmo perfil: afiliação, sucesso e poder, por ordem 
decrescente (Figura I). O vigor desta hierarquia pode ser interpretado a partir de vários dados empíricos complementares:

a) Ela é extensiva a estudantes universitários de uma grande diversidade de cursos (REGO, 1993, 1995, 1998a; REGO e CARVALHO, 2001, 2002), e a membros organizacionais de várias proveniências (REGO, 2000a).

b) Na amostra de gestores colhida por Rego (1995, 1998b), o perfil tende a reiterar-se, cifrando-se as cotações nos seguintes valores: 5.5 (sucesso), 5.6 (afiliação) e 4.5 (poder). Algo similar foi detectado na subamostra de gestores incluída no estudo de Rego (2000a): 5.6 (sucesso), 5.5 (afiliação) e 4.0 (poder).

c) Marques (2001), num estudo incidente sobre trabalhadores temporários, obteve uma configuração assim caracterizada: 5.4 (sucesso), 5.8 (afiliação) e 4.1 (poder).

d) Finalmente, a hierarquia justapõe-se ao perfil extraído por McClelland (1961, 1987), com o recurso à análise de conteúdo de material semântico: 0.13 (sucesso), 0.72 (afiliação) e -1.17 (poder).

Figura I

PERFIS MOTIVACIONAIS EXTRAIIDOS DE VÁRIOS ESTUDOS REALIZADOS EM PORTUGAL

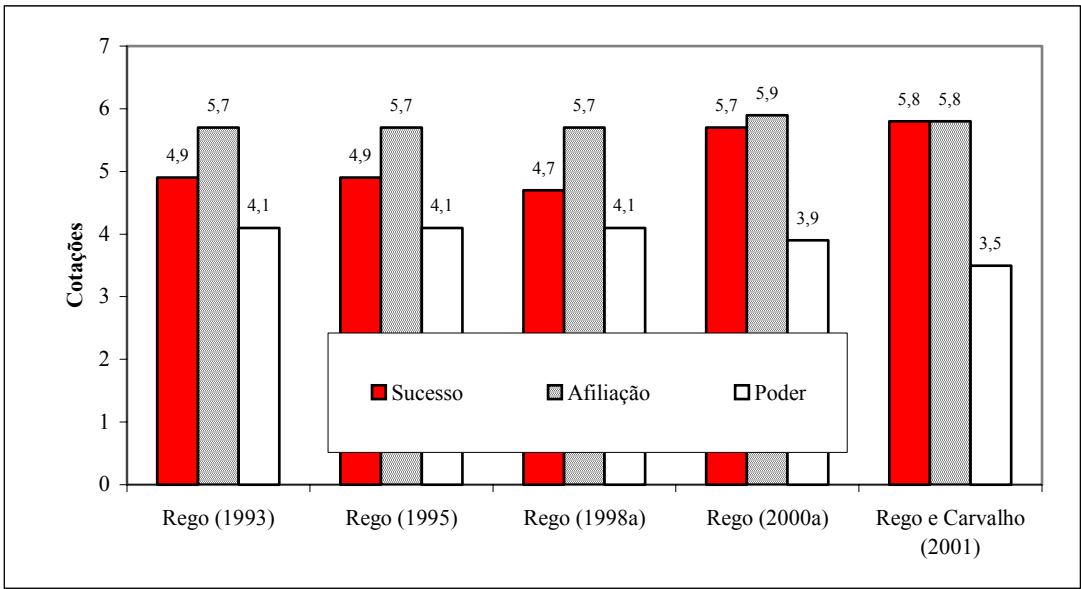

Importa porém frisar que o motivo de sucesso parece denotar um crescendo nos anos mais recentes, equiparando-se mesmo ao motivo afiliativo em algumas amostras (REGO, 2000a; REGO e CARVALHO, 2001, 2002). É possível que a evidência resulte das alterações efectuadas no questionário de medida dos motivos (a partir de REGO, 2000a, 
inclusive). Mas não deixa de ser também apelativa a possibilidade interpretativa de se estar a assistir à alteração do padrão motivacional português, porventura resultante de mutações nos padrões educacionais e/ou no quadro social, cultural e económico em que o país se tem vindo a inserir nos últimos anos. Uma explicação alternativa é, todavia, verosímil:

a) Há razões para supor que as alterações introduzidas no questionário de medida dos motivos (desde REGO, 2000a) aumentaram a sua validade psicométrica (do ponto de vista da estrutura dimensional e da consistência interna das escalas). Nessa lógica, será de presumir que o perfil por ele traçado corresponda mais à realidade do que o gizado pela versão inicial desse questionário.

b) Esta possibilidade converge com o facto de, no perfil traçado pelo teste de apercepção temática (REGO, 1993, 1995), os motivos de sucesso e de afiliação se posicionarem no mesmo patamar, surgindo distanciado o de poder: 0.38 (sucesso), 0.37 (afiliação) e 0.25 (poder).

c) Neste quadro de análise, parece então mais plausível que o perfil português denote um pendor mais direccionado para o sucesso do que as primeiras pesquisas de Rego fazem crer. Do ponto de vista do desenvolvimento económico, essa afigura-se uma "boa notícia" atendendo aos estudos reveladores de que o motivo está associado ao empreendorismo (MCCLELLAND, 1961, 1965; JOHNSON, 1990; SAGIE e ELIZUR, 1999) e ao desenvolvimento económico das nações (M CLELLAND, 1961; PEREIRA, 1980).

d) O caso não altera, porém, a notória força da motivação afiliativa na cultura portuguesa. E ajuda a interpretar a evidência que a seguir se expõe - a relativa aos perfis motivacionais dos gestores com impactes mais positivos junto dos seus colaboradores.

\section{PERFIL DE LIDERANÇA EM PORTUGAL - O SÍNDROMA "ENCLAVE PESSOAL"}

Os estudos que, tradicionalmente, procuram aferir o perfil motivacional mais conducente à eficácia de liderança tendem a sugerir a necessidade de uma elevada motivação para o poder (embora conjugada com elevada inibição da acção) e modesto pendor afiliativo. Na verdade, a elevada orientação afiliativa tende a ser associada a fraca eficácia de liderança (McCLELLAND e BURNHAM, 1976; KOESTNER e McCLELLAND, 1992; McCLELLAND, 1987): o indivíduo, preocupado em agradar e ser aceite pelos outros, em evitar conflitos e em manter ambientes de trabalho harmoniosos, acaba por adoptar comportamentos nefastos para a eficácia, designadamente: evita decisões impopulares 
ainda que necessárias, recompensa os colaboradores tendo em vista a aprovação social e não a recompensa do mérito, denota favoritismo para com os amigos.

Daqui decorre a proposta segundo a qual o perfil tendencialmente mais apropriado para a eficácia da liderança combina elevada motivação para o poder social e baixa motivação afiliativa. Sucede, porém, que uma elevada motivação afiliativa pode ser adequada em determinadas funções, designadamente as que exigem sensibilidade social, espírito de fomento da cooperação e harmonia interpessoal, e inclinação para a inter-ajuda (McCLELLAND, 1987). Pode também ser ajustada a países como Portugal, onde a afiliação atinge cotações elevadas e onde são numerosas as pequenas e médias empresas (muitas com características familiares e influenciadas por relações de vizinhança). Nesse caso, o padrão mais apropriado poderá ser o "Enclave Pessoal": o resultado combinatório de elevada motivação para o poder social e elevada orientação afiliativa (McCLELLAND, 1987, 1992).

Os dados empíricos obtidos por Rego $(1995,1998 b)$ tendem a confirmar esta hipótese. $\mathrm{O}$ autor relacionou os perfis motivacionais de gestores actuando em Portugal com os impactes por eles gerados nos seus colaboradores, tendo constatado o seguinte: a) os dois perfis motivacionais com impactes mais positivos eram fortemente orientados para a afiliação; b) o perfil gerador de melhores impactes caracterizava-se pela combinação de elevadas motivações para o poder e para a afiliação.

Acresce a saliência de um elemento emergente desse estudo de Rego: os impactes positivos "gerados" pelo motivo afiliativo parecem ser melhores nas empresas de tipo familiar do que nas restantes. Este dado aponta para a pertinência de se considerarem as especificidades de cada tipo de organização no contexto de uma mesma cultura nacional. E sugere a eventual alteração do perfil motivacional mais apropriado para a eficácia de liderança à medida que o tecido empresarial português se altera.

\section{COMUNICAÇÃO AFILIATIVA-RELACIONAL}

A literatura especializada tem sugerido diversas taxinomias para classificar os estilos comunicacionais (e.g., ALESSANDRA e HUNSAKER, 1993; CASSE, 1994; MCCALLISTER, 1994). Para os efeitos do presente texto, tomar-se-á como referência o modelo de Alessandra e Hunsaker (1993). Para ele existem dados empíricos extraídos por Rego (2001a), numa tentativa de providenciar um instrumento psicometricamente válido para medir os quatro estilos nele consagrados.

O modelo propõe duas dimensões básicas. A primeira suporta o binómio directo-indirecto. A segunda espraia-se entre os extremos auto- 
contido e aberto/social. Nos termos do quadro de sugestões exposto por Alessandra e Hunsaker (1993), eis a caracterização das dimensões:

a) A pessoa directa diz "o que tem a dizer", expressa a opinião facilmente, é assertiva, varia o tom de voz, denota gestos que enfatizam os pontos-chave que deseja expor, cumprimenta com firmeza, toma iniciativa social, toma riscos, olha firmemente olhos-nos-olhos, é combativa, orienta-se para a acção, prefere decisões rápidas, gosta de resultados, aparenta auto-confiança (por vezes, dominação), mostra-se impaciente.

b) $\mathrm{O}$ indivíduo indirecto ouve mais do que fala, é reservado nas opiniões e na partilha de sentimentos, é gentil no cumprimento, é parco nos gestos, é paciente, é socialmente pouco competitivo, medita nas decisões, evita grandes mudanças, atende a detalhes, é diplomático, adopta processos passo-a-passo, evita o conflito, não gosta de confrontar as suas ideias com as dos outros.

c) O indivíduo auto-contido orienta-se para os factos, auto-limitase na expressão de sentimentos e emoções, inflecte pouco a voz, gesticula pouco as mãos e o corpo, tem um discurso formal, gosta de manter a distância (física e psicológica), não gosta que invadam o seu "território", propende para factos e detalhes, é frio no trato, prefere trabalhar sozinho, tenta controlar o que está em seu redor.

d) A pessoa aberta/social é emocionalmente aberta, partilha sentimentos pessoais, sente-se bem em expressar alegrias e tristezas, expressa opiniões com facilidade, gosta de conversar, conta histórias e anedotas, tem expressões faciais animadas, gesticula com as mãos e o corpo, tem um discurso informal, mantém proximidade física, gosta do tacto, valoriza os sentimentos dos outros.

Do cruzamento das duas dimensões erguem-se quatro estilos típicos (figura II), cujas iniciais suportam a designação atribuída ao modelo (SARA): (S)ocial, (A)filiativo, (R)eflexivo e (A)dministrador. O estilo social/expansivo é propenso aos relacionamentos, à acção e extroversão. $\mathrm{O}$ afiliativo propende para as relações, o sentido da pertença social e a tranquilidade, mas é vagaroso e pouco decidido. O reflexivo caracterizase pela cautela nas acções e decisões, intelectualidade, trabalho isolado, gosto por detalhes, pouca propensão para o envolvimento pessoal. $\mathrm{O}$ administrador/senhor pende para o controlo, a acção, os resultados, o pensamento lógico, a mudança, descurando os relacionamentos e os sentimentos dos outros. Numa pesquisa englobando 457 indivíduos que foram convidados a descrever os perfis comunicacionais de alguém à sua escolha, Rego (2001a) constatou o seguinte: 
a) Considerando-se uma escala de eficácia comunicacional variando entre zero e vinte, os indivíduos menos directos (mais "diplomáticos") foram considerados comunicacionalmente mais eficazes do que os restantes (15.2 vs. 12.7; $\mathrm{p}<0.001)$. O mesmo sucedeu com os mais abertos/sociais relativamente aos que revelaram menor orientação para essa dimensão (11.6 vs. 15.4; $\mathrm{p}<0.001)$.

b) A grande maioria dos inquiridos (63\%) escolheu descrever alguém com estilo afiliativo/relacional.

c) $\mathrm{O}$ estilo considerado mais eficaz pelos inquiridos (figura II) foi também o afiliativo/relacional, seja do ponto de vista do indicador simples de eficácia (escala 0-20) ou do compósito (escala 1-7).

d) Ocorreu uma sobre-representação feminina nos estilos mais abertos/relacionais, o oposto ocorrendo nos dois estilos mais autocontidos (figura II).

\section{Figura II}

REPRESENTAÇÃO DOS INDIVÍDUOS DE CADA SEXO PELOS ESTILOS COMUNICACIONAIS, E COTAÇÕES DE EFICÁCIA COMUNICACIONAL ATRIBUÍDAS A CADA ESTILO (REGO, 2001A)

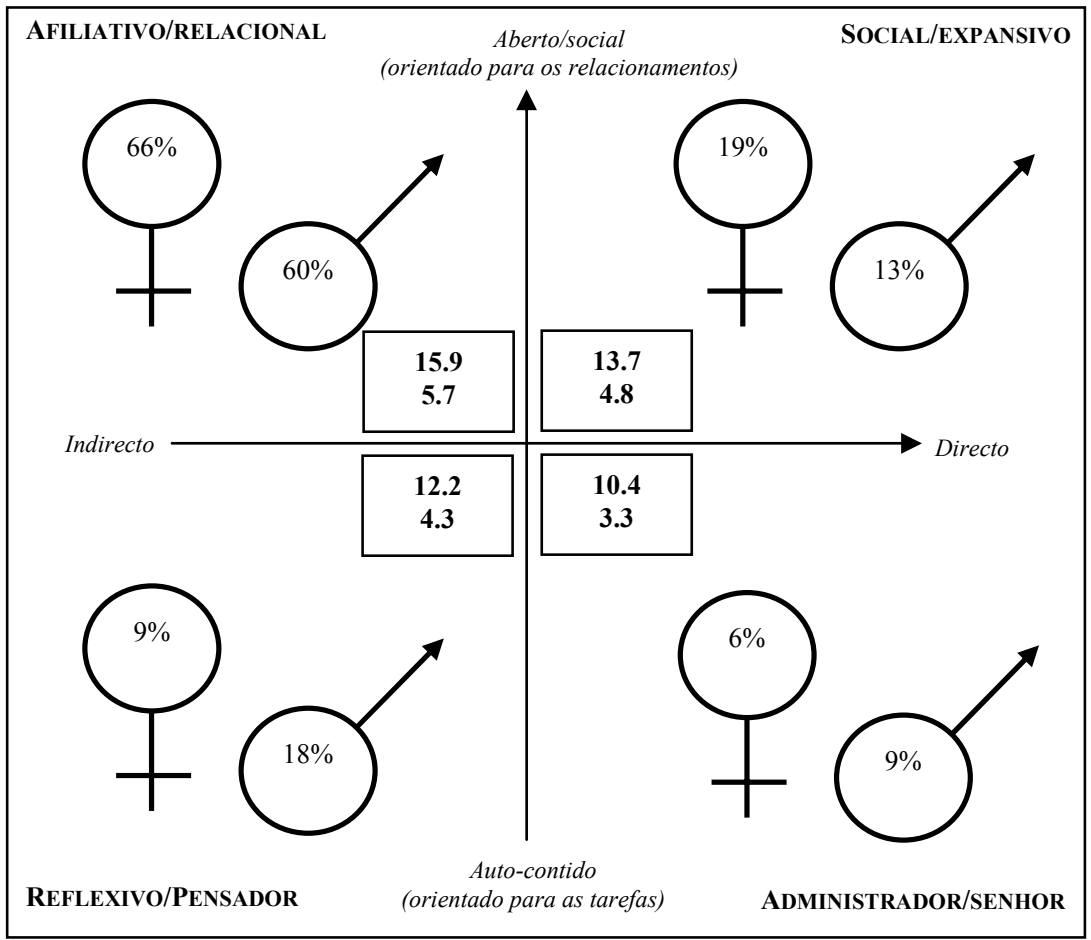


Os valores situados dentro dos círculos representam o modo como as pessoas de cada sexo se distribuem pelos quatro estilos (Qui-quadrado: 12,$19 ; \mathrm{p}=0,007$ )

Os valores situados nos rectângulos representam as cotações de eficácia comunicacional que os inquiridos atribuíram às pessoas cujos estilos descreveram: a primeira linha respeita a um indicador simples de eficácia (escala 1-20); a segunda linha concerne a um indicador compósito (escala 1-7)

\section{OUTROS ELEMENTOS ILUSTRATIVOS}

Para uma mais vasta e rica leitura do tema aqui em análise, os dados expostos podem ser complementados com diversa pesquisa empírica. Embora respeitantes a temáticas dispersas, eles auxiliam na compreensão do que parece ser um traço característico da cultura portuguesa. Eis um elenco de aspectos relevantes:

a) Cabe primeiramente registar o estudo recente efectuado por Rego (1999a) sobre os comportamentos de cidadania organizacional (ORGAN, 1988, 1997; REGO, 2002a). Tendo convidado 338 gestores a descrever os comportamentos de cidadania organizacional dos seus colaboradores, o investigador encontrou uma dimensão designada "Harmonia interpessoal" - raramente encontrada, pelo menos enquanto dimensão autónoma, na grande maioria das dimensionalizações efectuadas em estudos de projecção internacional e incidentes sobre amostras anglo-saxónicas (vide anexo 1 de REGO, 2002a). Curiosamente, uma dimensão homónima havia sido detectada por Farh e seus colaboradores (1997), ao estudarem os CCO em Taiwan. A semelhança é especialmente relevante pelo facto de Portugal e Taiwan denotarem perfis bastante semelhantes entre si (e simétricos dos perfis dos EUA e Grã-Bretanha) no que concerne às variáveis culturais de Hofstede (vide REGO, 2002a, p. 16).

b) Acresce que, entre as quatro dimensões de cidadania estudadas por Rego (1999a), a cotação nessa dimensão emergiu em lugar cimeiro (Quadro II). A tendência reiterou-se num estudo posterior efectuado pelo autor (REGO, 2000b), englobando 271 membros de várias dezenas de organizações portuguesas. 


\section{Quadro II}

COMPORTAMENTOS DE CIDADANIA ORGANIZACIONAL COTAÇÕES OBTIDAS EM DOIS ESTUDOS REALIZADOS EM PORTUGAL

\begin{tabular}{lll}
\hline & Rego (1999a) & Rego (2000b) \\
\hline Harmonia interpessoal & $\mathbf{5 . 2}$ & $\mathbf{5 . 3}$ \\
Conscienciosidade & 5.3 & 5.5 \\
Iniciativa individual & 4.8 & 4.8 \\
Identificação com a organização & 3.9 & 3.9 \\
\hline
\end{tabular}

c) Quando testou os poderes explicativos das percepções de justiça para esses comportamentos, Rego (2000b, 2000d, 2002b) verificou que a justiça social/interpessoal (grau em que as interacções com os superiores são consideradas justas) predominava sobre as facetas procedimental (grau em que os procedimentos são considerados justos) e distributiva (grau em que os resultados são percepcionados como justos). Essa evidência representou, aliás, uma tendência já antes decifrada numa amostra constituída por 182 colaboradores oriundos de 36 organizações (REGO, 2000c).

d) Numa investigação realizada com 319 indivíduos, Rego (1995) verificou que os estilos de gestão do conflito mais cotados eram os cooperativos (vide figura III). Essa tendência foi replicada na sub-amostra de 82 gestores abrangidos pelo estudo.

Figura III

COTAÇÕES NOS ESTILOS DE GESTÃO DO CONFLITO SUGERIDOS THOMAS $(1976,1992)$

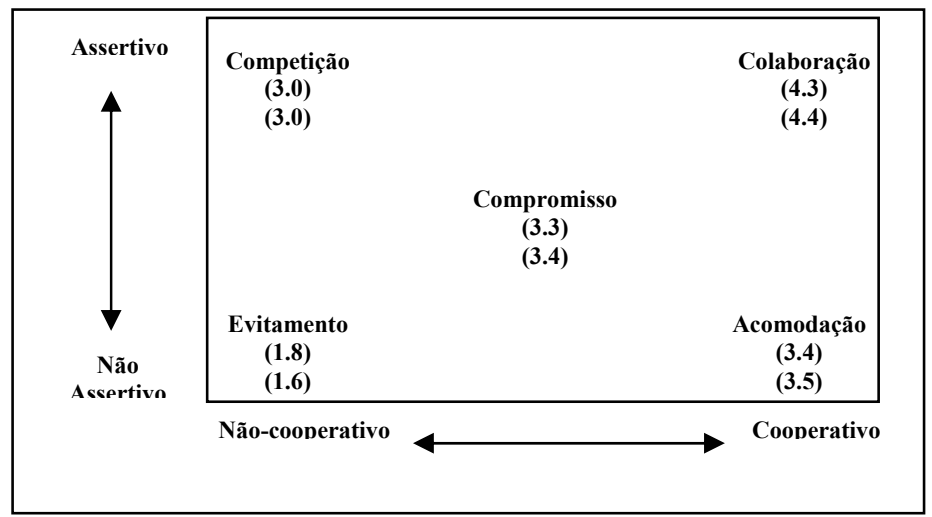

Entre parêntesis:

a) A primeira linha respeita à globalidade da amostra $(n=319)$

b) A segunda diz respeito à sub-amostra de gestores $(n=82)$

Fonte: Rego (1995) 
e) Quando pesquisou o poder explicativo das percepções de justiça para o empenhamento organizacional afectivo, numa amostra de 309 professores do ensino superior, Rego (2002c) notou que a vertente interaccional predominava sobre as restantes. $\mathrm{O}$ dado assume redobrada valia pelo facto de se estar perante membros organizacionais cuja actividade se caracteriza por elevada autonomia e reduzidas interacções com os superiores. O que tal evidência sugere é que, apesar disso, os indivíduos mantêm grande sensibilidade ao modo como se sentem tratados pelos seus superiores.

f) Finalmente, em vários estudos incidentes sobre quatro dimensões de comportamentos de cidadania dos professores universitários (conscienciosidade, comportamento participativo, orientação prática e cortesia), Rego e seus colaboradores (REGO e SOUSA, 2000; REGO, 1999b, 2001b, 2001c, 2002d) notaram que a dimensão mais cotada era a cortesia.

\section{IMPLICAÇÕES}

Os dados expostos merecem um conjunto de reflexões potencialmente frutuosas para a compreensão da cultura portuguesa e úteis para a extracção de linhas de orientação para as actividades de gestão:

a) O primeiro aspecto de meritória referência é o que concerne à lenta mudança das culturas nacionais. No que concerne a Portugal, tal é notório quando se tomam como referência os dados publicados por McClelland em 1961. Esses dados reflectiam os conteúdos das histórias relatadas às crianças cerca do ano de 1950, desenhando um perfil onde pontificava o motivo afiliativo, seguido da motivação para o sucesso sendo o poder relegado para último lugar. Os dados empíricos que Rego tem vindo a obter, desde há cerca de uma década, facultam um perfil em grande medida idêntico. Mesmo presumindo que tenha ocorrido um incremento na motivação para o sucesso, não deixa de ser significativo o facto de a motivação afiliativa permanecer em lugar proeminente e claramente superior à orientação para o motivo de poder. Este parece ser mais um indicador bastante categórico da lentidão evolutiva das culturas nacionais.

b) Realce-se que evidência exposta ao longo do texto parece gizar um traço muito característico: a elevada propensão para as relações sociais harmoniosas, a valorização da cooperação na gestão do conflito, a grande sensibilidade dos subordinados às relações "afiliativas" com os 
seus superiores e a tendência para comunicar de modo indirecto (pouco assertivo) embora social e emocionalmente aberto. A densa nuvem de elementos assim desenhada converge com o que foi enunciado por Hofstede $(1980,1991,1997)$ - parecendo, por conseguinte, justificável a denominação "feminina" para a cultura portuguesa.

c) A globalidade dos dados teóricos e empíricos aqui exibidos apela para a prudência perante as tentativas de aplicar num dado país as técnicas e modelos de gestão que revelaram ser proveitosas noutros países/culturas. Muitas dessas técnicas e modelos têm génese em culturas anglo-saxónicas claramente distintas da portuguesa, pelo que não podem merecer estranheza as ocorrências de fracasso nessas "importações" de modas (ABRAHAMSON, 1996).

d) O que os dados sugerem é que os gestores operando em Portugal necessitam de considerar as particularidades afiliativas da cultura nacional - tendo especiais cuidados nos estilos de liderança que exercitam com os seus colaboradores, no modo como comunicam com eles e procuram motivá-los, na maneira como premeiam o desempenho, nas estratégias a que recorrem para lidar com os conflitos. Sugerem, igualmente, que os gestores portugueses "expatriados" devem ponderar em que medida podem aplicar nos países de destino as "fórmulas de sucesso" em Portugal.

e) Importa acrescentar que a orientação afiliativa de uma dada cultura não parece impeditiva do desenvolvimento económico - como bem denotam os elevados índices económicos de diversos países nórdicos, tipicamente femininos no quadro classificativo de Hofstede.

Justifica-se, agora, uma nota de síntese reflexiva. O exposto não pode ser interpretado de modo linear, nem sequer como claramente denotador dos traços típicos da cultura portuguesa. $\mathrm{Na}$ verdade, as variáveis seleccionadas não respeitam, especificamente, a variáveis de natureza cultural. Acresce que não foram cotejadas com o que ocorre noutras culturas nacionais. E a grande maioria dos dados deve a sua paternidade aos trabalhos de um só autor. De qualquer modo, os dados convergem invariavalmente para o mesmo traço definidor: o teor afiliativo/relacional das relações interpessoais. Uma nota final, em jeito indagador: não estará o contraste entre as touradas portuguesa e espanhola bem reflectido no facto de a Espanha surgir, no estudo de McClelland (1961), com um perfil motivacional quase simétrico do português (poder, sucesso e afiliação, por ordem decrescente)? 


\section{BIBLIOGRAFIA}

ABRAHAMSON, E. (1996). "Management fashion". Academy of Management Review, 21, 254-285.

ALESSANDRA, T. e HUNSAKER, P. (1993). Communicating at work. New York: Simon e Schuster.

CASSE, P. (1994). "Revisiting communication: A 'new way' to manage it." European Management Journal, 12(3), p. 253-258.

FARH, J., EARLEY, P. C. e LIN, S. (1997). "Impetus for action: A cultural analysis of justice and organizational citizenship behavior in Chinese society". Administrative Science Quarterly, 42, p. 421-444.

GANNON, M. J. (2001). Understanding global cultures - metaphorical journeys through 23 nations ( $2^{\text {nd }}$ ed.). Thousand Oaks, CA: Sage.

HOFSTEDE, G. (1980). Culture's consequences. Beverly Hills: Sage.

HOFSTEDE, G. (1991). Cultures and organizations: Software of the mind. London: McGraw-Hill.

HOFSTEDE, G. (1997). Entrevista concedida à revista Executive Digest, Agosto, p. 40-41.

JOHNSON, B. R. (1990). "Toward a multidimensional model of entrepreneeurship: the case of achievement motivation and the entrepreneur". Entrepreneurship Theory e Practice, Spring, p. 39-54.

KOESTNER, R. e MCCLELLAND, D. C. (1992). The affiliation motive. In C. P. SMITH (Org.), Motivation and personality: Handbook of thematic content analysis (p. 205-210). Cambridge: Cambridge University Press.

MARQUES, I. (2001). A motivação e a satisfação dos recursos humanos em projectos temporários. Dissertação de mestrado em gestão de empresas. Faculdade de Economia da Universidade Nova de Lisboa.

MCCALLISTER, L. (1994). "I wish I'd said that!" How to talk your way out of trouble and into success. New York: Wiley.

MCCLELLAND, D. C. e BURNHAM, D. H. (1976). "Power is the great motivator". Harvard Business Review, March-April, p. 100-110.

MCCLELLAND, D. C. e KOESTNER, R. (1992). "The achievement motive". In C. P. SMITH (Org.), Motivation and personality: Handbook of thematic content analysis (p.143-152). Cambridge: Cambridge University Press.

MCCLELLAND, D.C. (1961). The achieving society. Pricenton, NJ: Van Nostrand.

MCCLELLAND, D.C. (1987). Human motivation. Cambridge: Cambridge University Press.

MCCLELLAND, D.C. (1992). "Motivational configurations". In C. P. SMITH (Ed.), Motivation and personality: Handbook of thematic content analysis (p. 8799). Cambridge: Cambridge University Press.

ORGAN, D. W. (1988). Organizational citizenship behavior: The good soldier syndrome. Lexington, MA: Lexington Books.

ORGAN, D. W. (1997). "Organizational citizenship behavior - its construct clean-up time". Human Performance, 10, p. 85-97.

PEREIRA, O. G. (1980). Psicologia económica: Disciplina do futuro. Universidade Nova de Lisboa, Faculdade de Economia.

REGO, A. e CARVALHO, T. (2001). "The achievement, affiliation and power motives: A confirmatory study of the three factor-model". Journal of Applied Psychology (Angewandte Psychologie), 3(4), p. 89-104. 
REGO, A. e CARVALHO, T. (2002). "Os motivos de sucesso, afiliação e poder Evidência confirmatória do constructo”. Psicologia: Teoria e Pesquisa, 18(1), p. 17-26.

REGO, A. (1993) "Níveis de motivação e graus de desempenho". Revista Portuguesa de Gestão, II, p. 69-82.

REGO, A. (1995). O modelo motivacional de McClelland - uma aplicação. Dissertação de Mestrado em Ciências Empresariais. Lisboa: ISCTE.

REGO, A. (1998a). "Motivações e desempenho de estudantes universitários". Análise Psicológica, 4, 635-646.

REGO, A. (1998b). "Configurações motivacionais dos gestores e respectivos impactes nos subordinados”. Revista Portuguesa de Gestão, I, p. 53-65.

REGO, A. (1999a) "Comportamentos de cidadania organizacional - operacionalização de um constructo". Psicologia, XIII(1-2), p. 127-148.

REGO, A. (1999b). "Cidadania docente universitária: A perspectiva dos diplomados". Revista Brasileira de Estudos Pedagógicos, 80(196), p. 404-415.

REGO, A. (2000a). "Os motivos de sucesso, afiliação e poder - desenvolvimento e validação de um instrumento de medida". Análise Psicológica, 3(XVIII), p. $335-344$.

REGO, A. (2000b). Comportamentos de cidadania organizacional. Uma abordagem empírica a alguns dos seus antecedentes e consequências. Tese de doutoramento, ISCTE, Lisboa.

REGO, A. (2000c). "Justiça e comportamentos de cidadania". Comportamento Organizacional e Gestão, 6(1), p. 73-94.

REGO, A. (2000d). "Comportamentos de cidadania organizacional - diferentes padrões reactivos às percepções de justiça". Organizações e Trabalho, 24, p. 9-28.

REGO, A. (2001a). Development and validation of an instrument for measuring the SARA model of communication styles. Paper presented at the $2^{\text {nd }}$ International Conference of the Iberoamerican Academy of Management, Mexico City, December 10-12.

REGO, A. (2001b). "Comportamentos de cidadania docente universitária: Operacionalização de um construto". Revista de Educação, X(1), p. 87-98.

REGO, A. (2001c). "O bom cidadão docente universitário: Na senda da qualidade no ensino superior". Educação e Sociedade (CEDES, Brasil), 75, p. 174-199.

REGO, A. (2002a). Comportamentos de cidadania nas organizações - um passo na senda da excelência? Lisboa: McGraw-Hill.

REGO, A. (2002b). "Climas de justiça nas organizações - sua relação com os comportamentos de cidadania". Caderno de Pesquisa em Administração (Faculdade de Economia e Administração, Universidade de São Paulo, Brasil), 9(1), p. 35-60.

REGO, A. (2002c). "Comprometimento afectivo dos membros organizacionais - o papel das percepções de justiça". Revista de Administração Contemporâne, 6(2), p. 209-241.

REGO, A. (2002d). "Citizenship behaviours of university teachers - the graduates' point of view". Active Learning in Higher Education, 4(1), p. 8-23.

REGO, A. e SOUSA, L. (2000). "Impactos dos comportamentos de cidadania docente sobre os alunos universitários - a perspectiva dos estudantes e dos professores". Linhas Críticas (Universidade de Brasília), 6(10), 9-30.

RETO, L. e LOPES, A. e CRUZ, J. (1989/1990). "Liderança política personalidades, conjuntura e representações". Revista de Gestão (ISCTE), VII, p. 13-17. 
SAGIE, A. e ELIZUR, D. (1999). "Achievement motive and entrepreneurial orientation: a structural analysis". Journal of Organizational Behavior, 20, p. 375-387.

THOMAS, K. (1976). “Conflict and conflict management”. In M. DUNNETTE (ed.), Handbook of industrial and organizational psychology. Chicago: Rand McNally College Publishing Company.

THOMAS, K. W. (1992). "Conflict and negotiation processes in organizations”. In M. D. DUNNETTE e L. M. HOUGH (Eds.), Handbook of industrial and organizational psychology (p. 651-717). Palo Alto, California.

WINTER, D. G. (1998). "A motivational analysis of the Clinton first term and the 1996 presidential campaign”. Leadership Quarterly, 9(3), p. 367-376. 